\title{
Medico-Legal Death Investigation Systems in the Pacific and Creating a Stronger Pacific Disaster Victim Identification Network
}

James JVP Kalougivaki ${ }^{*}$

Acting Head of Forensic Pathology, Forensic Science Service, Fiji Police Force, Fiji

*Corresponding author: James JVP Kalougivaki, Acting Head of Forensic Pathology, Forensic Science Service, Fiji Police Force, Fiji, Tel: 679 9905 601; E-mail: james.kalougivaki@gmail.com

Rec date: Oct 8, 2014, Acc date: Nov 20, 2014, Pub date: Nov 24, 2014

Copyright: (c) 2014 Kalougivaki JJVP. This is an open-access article distributed under the terms of the Creative Commons Attribution License, which permits unrestricted use, distribution, and reproduction in any medium, provided the original author and source are credited.

\begin{abstract}
Introduction: The Pacific Island Countries (PICs) consist of 20,000 to 30,000 scattered islands spread across 8.5 million square kilometers of Ocean. There are three ethnogeographic distinct sub-groupings in the Pacific and they are Polynesia, Melanesia and Micronesia. The evolution of the global Medico-Legal Death Investigation (MDI) system has produced the Coroner's, Medical examiner's and the newer European Continental systems. However, the PICs maintain post-colonial mixed medico-legal systems. Disaster Victim Identification (DVI) is an important part of the MDI system.
\end{abstract}

Objective: To review the MDI systems in the PICs and the recommend measures accordingly to strengthen the network for DVI in the Pacific.

Methods: This is a qualitative research paper focusing on independent self-governing PICs from Polynesia, Melanesia and Micronesia.

Discussion: The PICs criminal codes, legal systems and post-colonial adaption of MDI systems are emerging. There are also many developmental limitations for MDI systems in the PICs. Despite the profound historical evidence of disasters of varying magnitudes, the Pacific MDI and DVI network exists as an informal one through personal acquaintance. Therefore, this demands a better and effective MDI system in the PICs particularly with regards to DVI.

Conclusion: The need to fortify and better the DVI network in the Pacific will depend on good regional indicators. There is a crucial need for the operatives of the MDI system in the PICs to form a link through intergovernmental participation and association with other Pacific networks to drive the sustained development of the national and regional MDI system. Through this collaboration the Pacific DVI network could also be established centrally in a PIC that has a steady Forensic Science Service. Upcoming Forensic experts could operate out of this central location to serve the PICs accordingly. This eventually will achieve a standard practice and regionalization of the Pacific MDI network.

Keywords: Pacific; Medico-legal; Death; Disaster; Victim

\section{Introduction}

The Pacific Island Countries (PICs) consist of 20,000 to 30,000 scattered islands spread across more than 8.5 million square kilometers of Ocean (quarter of the earth's surface) and is $98 \%$ is Ocean [1]. PICs can be divided into three ethnogeographic distinct sub-groupings: Polynesia, Melanesia and Micronesia, but excludes the neighboring island continent of Australia and the Asia-related archipelagoes [2]. Melanesia meaning 'black islands', south of the equator, includes Papua New Guinea (PNG), the Solomon Islands, New Caledonia and Vanuatu. Fiji is part of Melanesia due to location but its culture is more Polynesian. Micronesia means 'small islands' and is more than 2000 low-lying coral islands north of Melanesia and the equator with islands inclusive of Guam, the Caroline Islands, the Mariana Islands, the Marshall Islands, Kiribati, and the single island of Nauru. Polynesia means 'many islands', occupying the largest area in the South Pacific inclusive of the Cook Islands, Kiribati, Niue, Samoa, Tokelau, Tonga and Tuvalu (Figure 1)

The medico-legal death investigation (MDI) system is the interface of medical science with law and public policy and literally involves the Police, the Judiciary and Forensic specialists. The outcome of the MDI systems is to investigate manner and cause of unexpected, unexplained, unnatural, sudden and suspicious deaths (accidents, suicides, homicides or undetermined) $[3,4]$. This system drives the Public and Curative Health, formation common laws, acts of parliament, parts of the constitution and last but not the least, research. On a more important note the MDI systems should be competent, credible and of the highest quality possible to ensure that justice is served to the secondary victims.

The MDI systems are therefore, essential and valuable components of development of a nation. Sir William Gladstone knew the depth in death investigation when he said "Show me the manner in which a nation cares for its dead and I will measure with mathematical 
exactness the tender mercies of its people, their respect for the laws of the land, and their loyalty to high ideals."

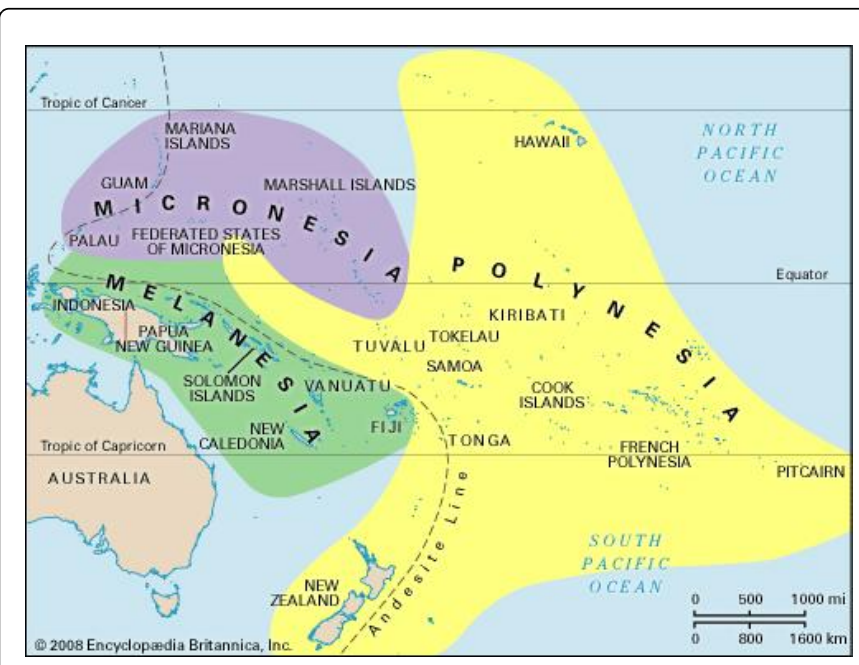

Figure 1: Pacific Island Countries and sub-grouping. (Source Encyclopedia Britannica, Inc.)

- For MDI systems to be effective they should have the following traits $[5,6]$.

- Independent to all other parties involved.

- Laborious in function but compliant to human rights or specifically the Articles 6 to 23 of the International Covenant on Civil and Political Rights.

- Have a well-resourced inquisitorial court as possible and chaired accordingly.

- Achieve a recommendatory role and operate in partnership with institutions and governments.

- Should be supported by the forensic specialist science units to ensure efficiency in investigation and resolution of the death investigation for the sake of justice and, to be the counter therapeutic potentiation of grief.

Generally, legal systems basically have two main systems with European origins and have been used by most countries in the world either through a post-colonial inheritance or by direct adoption. These legal systems form the foundations of a MDI system. The first system is that of English legal practice, advanced from pre-existing AngloSaxon laws whilst the second system is that of European Continental law originating from Roman Law and strongly influenced by the Code Napoleon [7].

\section{The main MDI systems include the:}

1. Coroner's system: This is a medical and scientific investigation combined with judicial enquiry in open court with its origins said to go back to the Council of Eyre in $1194[8,9]$.

2. Medical examiner's systems: In this system the combined medical and scientific examination is conducted in private without a judicial enquiry e.g. the Medical Examiner system in the USA.

3. Newer Continental (European) systems: This system involves a police-initiated and orientated process where a law enforcement agency enquiry is sometimes combined with medico-legal, scientific expert investigation, judicial investigations [7] e.g. the Procurator Fiscal system of Scotland.

Also saw the progression of medical jurisprudence or forensic or legal medicine [7].

As the medico-legal systems modernized this also saw the focus on Disaster Victim Identification (DVI) processes that involved the collaboration of multiple Government and Non-government agencies. DVI sees the forensic scientific community working together with the respective Police and Legal departments to ensure victims of disasters are identified. DVI in brief involves the Scene, Ante- and the Postmortem phases. The Reconciliation phase basically involves the presentation of the victim identity after reconciliation by an Identification Board to the Coroner or magistrate to make the final determination as to the identity of the deceased.

\section{Colonial influence on legal and MDI systems in the PICs}

To understand the current legal and MDI systems in the Pacific one must have an idea about the transition of PIC legal status during the colonial and decolonization or post-independence periods of the islands. Britain, France, Germany, Spain and the United States of America (USA) in the late 1800s colonized PICs established their respective laws in the colonies.

Germany and the USA took control of Micronesia after 1898. In the early 1900s Germany also held parts of Nauru, New Guinea and Samoa whilst the USA controlled Hawaii and the rest of Samoa. France controlled New Caledonia and French Polynesia and shared control of the Vanuatu with Britain. Fiji, Papua, Tonga, the southern Solomons, Kiribati and Tuvalu were under British control. Japan took control of German property in Micronesia after Germany's defeat in World War I, New Zealand took over German Samoa, and Australia took control of northeastern New Guinea [10,11].

Samoa gained independence from New Zealand in 1962 but the Cook Islands and Niue became self-governing in free association with New Zealand in 1965 and 1974 respectively. Nauru became independent in 1968 after being a trust territory of Australia, Britain and New Zealand. In 1970, Fiji and Tonga gained their independence from the United Kingdom followed by Papua New Guinea in 1975 from Australia [11]. The Solomon Islands and Tuvalu gained their independence in 1978 and thereafter, Kiribati in 1979 and Vanuatu in 1980. Marshall Islands, Palau and the Federated States of Micronesia became independent nations in free association with the USA in 1994. Tokelau remains under New Zealand's administration since 1925 [12].

For independence all PICs except Tokelau prepared and enacted constitutions to be the supreme law accordingly based on their preexisting or colonial laws during independence [13]. There are other apparent influences in the formation of laws in the PICs today like international security, international trade, good governance, international human rights and the "Westminster" system that are slowly displacing religion, customs and traditions. This is evident in Fiji where the word "Fijian" was previously used to refer to the indigenous race which is now used collectively for all Fiji citizens to encourage multiracialism.

Therefore, generally all PICs have a pluralistic legal system having several different kinds of laws derived from several different sources and these include [14]:

Written constitution to be the supreme law. 
Written legislation enacted by the legislature of the country either during the period of dependency, or since independence or selfgovernance, and subsidiary legislation authorized by that legislation.

Written legislation enacted by the legislature of the former colonial power and applied to, or adopted by, the dependent country, and subsidiary legislation authorized by that legislation.

Written and unwritten rules of custom and customary law, and

Unwritten rules of common law and equity.

\section{Objective}

To review the Medico-Legal Death Investigation systems in the PICs and the recommend measures accordingly to strengthen the network for DVI in the Pacific.

\section{Method}

This is a qualitative research paper focusing on independent selfgoverning PICs from "Polynesia" (Cook Islands, Niue, Tonga, Tuvalu, Kiribati, and Samoa), "Melanesia" (PNG, Vanuatu Solomon Islands, Fiji) and "Micronesia" (Federated States of Micronesia, Republic of Marshall Islands, Nauru, Palau). Also inclusive of New Caledonia and French Polynesia but exclusive of Australia and New Zealand who have well established MDI systems.

\section{Discussion}

Generally, the PICs have limited resources and local expertise in the area of developing and strengthening the MDI system. The PICs criminal codes, legal systems and post-colonial adaption of MDI systems are still emerging.

MDI systems do play a vital role in nation building particularly if the MDI statistics are collated well and interpreted to outline autopsy based mortality trends. This could indicate improvement, stagnation or worsening status of a nation's health situation. Therefore, there is a need to develop a registry for MDI in the PICs so as to aid the development of credible primary sources of mortality for the region [15]. A study revealed the urgent need to improve infrastructure, training, and resources for routine mortality estimation in many PICs in order to better inform and evaluate health and public policy [16]. In 2013 the Fiji Police Force recorded 108 suicides from the 739 total number of autopsy deaths. This was fifty more suicidal deaths as compared to those suicides in 2009 [17]. The sharp increase in suicides should prompt relevant authorities to analyze the data and put up counter measures for future attempts of suicides.

Improved MDI data collection and dissemination would ensure that MDI systems in the PICs also contribute to society by a clear recommendatory and legislative function. Also information from MDI statistics is vital for the reformation of the national MDI system and eventually, formation of a stable functional Pacific MDI network.

\section{Criminal codes in the PICs}

Criminal codes are the basis for a country's jurisdiction and in particular the criminal or civil laws. The "Stephen code", prepared by Sir James Stephen in England became the basis for the New Zealand Crimes Act [18] and the criminal codes of Cook Islands, Niue, Samoa and Tokelau [19]. The "Griffith code" was prepared by Sir Samuel Griffith and was first enacted in Queensland [20] and then later passed on to Nauru [21] and PNG [22] from Australia. It was also used by British officials in the Colonial Office as a model to be applied in Fiji, Kiribati, Solomon Islands and Tuvalu [23]. In the Pacific, Tonga and Vanuatu have different unique criminal codes [24]. The Stephen and Griffith codes continue to be used as basis for the law of criminal offences despite decolonization in the PICs.

\section{Legal systems in the PICs}

Most of the jurisdictions of the South Pacific basically have two levels of criminal courts that are formally separate and are termed differently from nation to nation. The former New Zealand dependencies of Cook Islands and Niue provide partial exceptions [25].

The title 'High Court' is the higher level of court used in former British dependencies like Fiji Islands, Kiribati, Solomon Islands, Tuvalu [26] and also used in Niue [27]. For Tokelau, the relevant court is the High Court of New Zealand [28]. The title 'Supreme Court' is used in Nauru, Samoa, Tonga and Vanuatu [29] while in PNG, the term is 'National Court', with 'Supreme Court' being used [30].

Most commonly in the PICs the lower level of court is called a 'Magistrate's Court' [31] but the chosen term in Nauru and PNG is the 'District Court' [32]. Overall, magistrates in the PICs have a fairly broad jurisdiction and the legal systems and MDI processes in the PICs are outlined below.

\section{Melanesia}

The Melanesian group court system and legal system are fundamentally formed from post-colonial inheritance. PNG has a mixed legal system of English common law with customary law and a Magisterial Service guided by a Coroner's Manual and Corner's Act of 1954. The Coroners Manual is the guide that covers the MDI areas accordingly [33]. Fiji is one of the most developed Pacific island countries with a well-established modern judicial system [34]. Fiji's common law system is based on the English model and has the Magisterial Service, Police Force and Forensic specialists conducting MDI according to the Inquests Act of 1968. With regards to the MDI it is initiated by the Police or the Magistrate respectively. Vanuatu has a mixed legal system of English common law, French law, and customary law, with a Commissions of Inquiry Act and coroners system catering for MDI [35]. The Coronial system in the Solomon Islands is directed by the Death and Fire Enquiries Act but it was noted in the report that practitioners, police and magistrates often lack understanding of the functions of a coroner [36]. Solomon Islands' legal system is a mixed legal system of English common law with customary law. The French State is responsible for the administration of justice in New Caledonia. Therefore, New Caledonia shares a similar judicial system to the French State and with regards to death investigation a type of continental system is applied.

\section{Polynesia}

All of the jurisdictions of the South Pacific region, with the exception of Tokelau, have written constitutions [37]. Also to note that in Polynesia, Tonga and Samoa are Constitutional Monarchies. Niue and Tonga uses the Inquests Act of 1964 and 1988 respectively that includes the Coroner's duties and both these PICs have legal systems based on the English common law. Tuvalu has a Death and Fire Enquiries Act, Kiribati has a Death and Fire Enquiries Ordinances and Samoa has a Coroners Ordinance of 1959 and Coroners Bill of 2014 
[38]. Tuvalu, Kiribati and Samoa have mixed legal systems of English common law with customary law. Death investigative processes or systems are not like the full standard coronial system and are a little rudimentary in comparison. Cook Islands have the Holding of Inquests Regulations of 1923 under the Cook Islands Amendment Act 2007 based on common law similar to that of New Zealand common law.

In brief the Polynesian medico-legal systems though still developing have similarities to the early continental European style of the MDI systems. The legal system in French Polynesia uses the laws of France where applicable.

\section{Micronesia}

The Federated States of Micronesia (FSM) and the Marshall Islands are independent but in free association with the United States and the judiciary respectively employs an adversarial process [39]. The FSM has a mixed legal system of common and customary laws whilst the Marshall Islands has a mixed legal system of the USA and English common laws [39].

Therefore, in brief the medico-legal processes and legal systems in the PICs are mixed or pluralistic in nature. The MDI are basically initiated by the Police and the Medical Officers with the inquests are dealt with at the Magistrate courts in an inquisitorial manner except for those PICs mentioned from Micronesia.

\section{Disasters in the PICs}

Disasters both Human-induced and Natural have resulted in the loss of thousands of lives in the Pacific and have detrimental impact to the economy of the PICs affected.

\section{Natural Disasters}

The PICs face some of the largest annual losses from disasters worldwide and these losses range from $1.5 \%$ to $6.5 \%$ of the GDP or an average estimate of US $\$ 278$ million dollars annually [40]. The PICs have had more than 2,400 tropical cyclones in the past 60 years and this has greatly affected the forward drive of the economy due to huge losses in major sectors like agriculture, water, infrastructure, health and fisheries.

According to a report, tropical cyclones (50\%), earthquakes (31\%) and floods $(11 \%)$ cause the most peril to the PICs with Papua New Guinea (27\%), Fiji (21\%), Vanuatu (13\%), Solomon Islands (11\%) and Tonga (7\%) being the most affected [41]. This is because these PICs plus the FSM, Marshall Islands and Cook Islands geographically sits within the Pacific 'Ring of Fire'.

Some examples of these natural disasters include the 23 foot tidal wave that hit PNG in July 1998 following a 7.0 magnitude earthquake at the Solomon Islands killing 2,500 to 3,000 people and a massive landslide in PNG in January 2012 killing 60 people.

\section{Human-induced disasters}

Small scale: Small scale human-induced disasters include fatal road traffic or any modes of transport accidents, discovered skeletonized remains and gun associated deaths like that of the Southern Highlands of PNG that have a 6.2 annual rate of gun homicides per 100,000, which is higher than that of the USA [41].
Large scale: Include those human-induced disasters of a larger magnitude that can rapidly destabilize a nation.

1. Fatal Accidents: Like the 17 occurrence of aviation accidents and crashes by various operators since September 1943 to April 2010 that resulted in the total of fifty six fatalities [42].

2. Politically or racially motivated events: Like those listed below:

- Coup in Fiji: These include the military coups of 1987 (two) and 2006 , and a single civilian coup in 2000 . These coups were strongly associated with ethnic tension between the indigenous Fijians and the Indo-Fijians who originally came to Fiji as indentured labor in the late nineteenth and early twentieth century [43].

- Bougainville civil war: An estimated 10,000 people died during the 10 year civil strife and most of the dead were non-combatants who died from untreated diseases.

- Solomon Islands: In early 1999 long-simmering tensions between the local Gwale people on Guadalcanal and more recent migrants from the neighboring island of Malaita [44] erupted into violence and had already resulted in the death or serious injury of 30000 civilians.

\section{Regional order and networks in the PICs}

In 1971 on the initiative of Fiji, the South Pacific Forum was formed by Australia, New Zealand and 13 other independent self-governing PICs and was renamed Pacific Islands Forum in 2000. Since 2006, associate member territories are New Caledonia and French Polynesia [14,45]. The Pacific Islands Forum is one of the regional bodies that has no supranational power or authority but is at the center of diplomatic and economic development of the PICs.

Other relevant Pacific and International organizations or networks include the International Committee of the Red Cross (ICRC), Asia Development Bank, Pacific Disaster Risk Management Partnership Network (PDRMPN), Secretariat of the Pacific Community (SPC), the University of the South Pacific (USP) and the Asia Pacific MedicoLegal Agencies (APMLA). The formal creation of the APMLA network was in Melbourne, Australia, in October 2008 and this was led by the Victorian Institute of Forensic Medicine (VIFM), the ICRC and the Australian Federal Police (AFP). It was formed to cater for man-made and natural catastrophes in the Asia-Pacific region [46].

With regards to the PICs there is no formally established Forensic Scientific Community network or secure regional understanding between all the medico-legal bodies of the respective PICs.

Despite the profound historical evidence of disasters of varying magnitudes, the Pacific MDI and DVI network exists as an informal one through personal acquaintance and not as an intergovernmental collaboration. Therefore, this demands a better and effective MDI system in the PICs particularly with regards to DVI. There is no set treaty or convention to allow for a general regional standard response to a MDI of any magnitude in the Pacific despite the increasing need to establish one. Some of the reasons for the current MDI or DVI network status include:

Infancy of the MDI service in the PICs.

Absence or lack of Forensic Pathologists and other Forensic experts in many PICs. This also includes the absence or lack of Forensic laboratory facilities that aid the MDI.

Lack of attention and support to the respective local Forensic Scientific practitioners by the national governing authorities. 
Non-independent status of the MDI system in the respective PICs.

Infrequent creation or reformation of national inquest procedures, legislation, policies and processes with regards to the MDI system.

Poor association or affiliation of currently established MDI systems to national or regional academic (medical) institutions.

Lack of a formal Forensic specialist education or attachment overseas for local Forensic Science practitioners. This tends to be due to limited resources, and the lower priority status of Forensics.

Fragile international support and awareness from existing well established MDI institutions and agencies of the developed countries. International bodies, like INTERPOL, basically produce DVI materials generally accepted and used in the world but these material applications are not fully understood within the PICs. Technological support will also drive operations in DVI to better levels.

Absence of a medico-legal autopsy based death registry.

Great diversity in culture, customs, legal systems and post-colonial influence along with languorous development of all types in the PICs.

\section{Future of DVI in the Pacific}

Every DVI operation is subject to the laws of the country in which the disaster in question occurs [47]. In view of the limitation of the MDI system in the PICs, there is a great need for accelerated growth in the area of DVI due to the wide range of disastrous events noted historically. This will require the integration of current standard practice of the phases of DVI, particularly the antemortem and reconciliation phases into the MDI systems and legislation of the PICs. This will ensure formal agreements for proper and convenient retrieval of antemortem data from victims' home countries, formal cooperation with overseas Forensic institutes, Federal Police and governments in all phases of the DVI process, training of Forensic experts in PICs and reformation of the coroner's or magistrate's roles in the final determination of the victim's identity.

The development of DVI in the PICs requires supra-national cooperation or understanding to ensure a proper regional approach to national and regional disasters. In this way the intergovernmental cooperation between the PICs will allow for the formation of a DVI network in conjunction with existing Forensic networks, institutes and relevant Pacific or International organizations.

There has been increasing support from the Australian and New Zealand governments through their respective Federal Police Departments and institutes like the Victoria Institute of Forensic Medicine (VIFM) over the years to increase capacity building and training in DVI through the provision of advice, training and mentoring with their forensic capability [48].

\section{Conclusion}

The need to fortify and better the DVI network in the Pacific will depend on regional indicators:

Stable or good governance.

Constant progressive reviews of National MDI processes with the support of technical advisors.

The presence of Forensic experts in the PICs.
The support from National governing authorities and wellestablished international bodies concerned with DVI and MDI systems.

Scale and magnitude of the disaster with the subsequent fatalities.

Pacific MDI and DVI service network creation and cooperation.

Intergovernmental cooperation between the PICs to drive the development of MDI systems.

In particularly, there is a dire need for the reformation of court or legal systems and the inquest or coroner's procedures in the PICs to incorporate standard MDI and DVI phases. Therefore, now is certainly an opportune time to re-imagine the future of law in the Pacific Islands to cater for and empower the acceptable practice of DVI through a proper MDI system. This can be achieved by extensive review and understanding of current legislation [49] in the PICs by formal discerning innovative appraisals to ensure development of the legal system [50].

There is also a crucial need for the operatives of the DVI and MDI system in the PICs to meet and form a link. For this link to progress into a stronger formal regional DVI network there has to be an intergovernmental participation to drive the development of the national and regional MDI system.

Furthermore, the sustainability of the Pacific DVI and MDI network depends on the presence of a pool of Forensic experts, respective National MDI system reviews by technical advisors and the association with other relevant Pacific networks and organizations.

Through collaboration with other regional networks and governmental cooperation, the Pacific DVI network could also be established centrally in a PIC that has a Forensic Science Service. Upcoming Forensic experts could operate out of this central location to serve the PICs. This practice will be ongoing to achieve a standard practice and regionalization of the network with the input from established neighboring Forensic Institutes or Services and agencies. There is a notion that despite diversity in culture and post-colonial influence along with languid development of all types, the PICs has so much potential to progress together in regards to a MDI system because of a general communal Pacific spirit that surpasses political and economic planes, hence this would be the key uniting factor of the Pacific DVI network.

\section{References}

1. "The Geography of Oceania". About Education. 2014. Web. (accessed 28th August 2014)

2. $\quad$ "Pacific Islands". Encyclopædia Britannica. Encyclopædia Britannica Online. Encyclopædia Britannica Inc., 2014. Web. (accessed 28th August 2014).

3. Saukko P (1995) Medicolegal investigative system and sudden death in Scandinavia. Nihon Hoigaku Zasshi 49: 458-465.

4. Moldovan E (2008) "The Medicolegal Death Investigator: An Evolution in Crime Scene Investigations Relating to Unexpected Deaths" Proquest.

5. Freckelton, Ian R (2013) Death Investigation, Coroner's Justice and Human Rights: Australian Perspectives. In: Indo Pacific Association of Law, Medicine and Science Congress. Globalization in Forensics, 7 - 10 October 2013, Kuala Lumpur, Malaysia. Malaysia; 2013.

6. Freckelton I (2007) Death investigation, the coroner and therapeutic jurisprudence. J Law Med 15: 242-253.

7. Rao D (2013)History of Medicolegal System. 
Citation: Kalougivaki JJVP (2015) Medico-Legal Death Investigation Systems in the Pacific and Creating a Stronger Pacific Disaster Victim Identification Network. J Forensic Res 6: 255. doi:10.4172/2157-7145.1000255

Page 6 of 6

8. Freckelton, Ian R, and David Ranson (2006) Death Investigation and the Coroners Inquest. South Melbourne, Vic: Oxford University Press.

9. Spitz, WU (2006). Medicolegal Investigation of Death: Guidelines for the Application of Pathology to Crime Investigation (4th Ed)(4th Edition ed.). Springfield, Il: Charles C. Thomas.

10. Wilberforce JA (1941). Affairs in the Western Pacific. In Bean, Charles Edwin Woodrow. Official History of Australia in the War of 1914-1918. Official Histories, Australian War Memorial. Volume IX - The Royal Australian Navy: 1914 - 1918. 9th ed. Sydney, Australia: Angus and Robertson; 129-149.

11. Murgatroyd Peter (2006) "Introduction to Researching South Pacific Law”. GlobaLex. Web (accessed 24th August 2014).

12. Denoon, Donald, Firth, Stewart. (2008) The Cambridge history of the Pacific Islander. Cambridge: Cambridge University Press.

13. Bird R (2001) "Features - Update to Law of the Pacific Islands: A Guide to Web Based Resources". (accessed 2nd September 2014).

14. Angelo AH (2006) "Legal Capacity in Pacific Island Countries". In: N Boister and A Costi (eds). Regionalising International Criminal Law in the Pacific. NZACL/ALCPP, Wellington; 71-92.

15. Linhart C, Carter K, Taylor R, Rao C, Lopez A (2014) Mortality Trends in Pacific Island States. Secretariat of the Pacific Community.

16. Taylor R, Bampton D, Lopez AD (2005) Contemporary patterns of Pacific Island mortality. below Int J Epidemiol 34: 207-214.

17. Fiji Facts and Figures as at 1st July 2010. Fiji Islands Bureau of Statistics, Suva, Fiji.

18. First enacted as the Crimes Act 1893 (NZ). See now the Crimes Act 1961 (NZ). The Stephen code was also adopted in Canada. See Criminal Code 1892 (Can); Criminal Code, RSC 1985, c C-46.

19. Crimes Act 1969 (Cook Islands); Niue Act 1966 (NZ), Part V, as preserved by Constitution of Niue, Art 71; Crimes Ordinance 1961 (Samoa); Tokelau Crimes Regulations 1975 (NZ), adopting the criminal law provisions of the Niue Act 1966 (NZ).

20. Criminal Code Act 1899 (Qld), Sch 1.

21. Nauru has taken the Criminal Code (Qld), with amendments in force on 1 July 1921, through the Laws Repeal and Adopting Ordinance 1922-67 (Nauru), s 12.

22. Criminal Code [Cap 262] (PNG).

23. Penal Code [Cap 1]7 (Fiji Islands); Penal Code [Cap 67] (Kiribati); Penal Code [Cap 26] (Solomon Islands); Penal Code [Cap 8] (Tuvalu).

24. Criminal Offences Act [Cap 18] (Tonga); Penal Code [Cap 135] (Vanuatu).

25. Judicature Act (1980-1981) (Cook Islands) ss 13, 19-22; Constitution of Niue, ss 37, 48(1) ('commissioners'), 51(2) ('justices').

26. Constitution Amendment Act 1997 (Fiji Islands) s 120; Constitution of Kiribati, s 80; Constitution of Solomon Islands, s 77; Superior Courts Act [Cap 1C] (Tuvalu).

27. Constitution of Niue, art 37.

28. Tokelau Amendment Act 1986 (NZ) s 3.

29. Courts Act 1972 (Nauru) s 17; Judicature Ordinance 1961 (Samoa) s 31 Supreme Court Act [Cap 10] (Tonga); Courts Act [Cap 122] (Vanuatu) ss $23-23$.
30. Constitution of the Independent State of Papua New Guinea, ss 160-167.

31. See Magistrates' Courts Act [Cap 14] (Fiji Islands); Magistrates' Courts Ordinance [Cap 52] (Kiribati); Magistrates' Courts Act 1969 (Samoa); Magistrates' Courts Ordinance [Cap 20] (Solomon Islands); Magistrates' Courts Act [Cap 11] (Tonga); Magistrates' Courts Ordinance [Cap 2] (Tuvalu); Courts Act [Cap 122] (Vanuatu) ss 1-12.

32. [127] Courts Act 1972 (Nauru) s 18; District Courts Act 1963 (PNG). On the citation of the PNG statute, see Donald Chalmers, David Weisbrot, Salamo Injia, Warwick Andrew, Criminal Law and Practice of Papua New Guinea (3rd ed, 2001), p 66.

33. Papua New Guinea - Coroners Manual Coroners Act. June 2004. Pacific Islands Legal Information Institute. Web. (accessed 10th September 2014).

34. Anon (2009) "Traditional Justice Systems in the Pacific, Indonesia and Timor-Leste". In: UNICEF. UNICEF Papua New Guinea for the 2009 Justice for Children in the Pacific, Indonesia and Timor-Leste, EAPRO Sub-Regional Workshop. Papua New Guinea.

35. Vanuatu. Pacific Islands Legal Information Institute. (22 September 2014). Web. (accessed 23rd September 2014).

36. Report on Attendance at the 16th Annual Australasian Coroners' Society Conference, December 2006. Web. (accessed 28th August 2014).

37. Constitution of Niue, s48(1); Tokelau Amendment Act 1986 (NZ) s 7.

38. Pacific Islands Legal Information Institute. (22 September 2014). Web. (accessed 23rd September 2014).

39. The World Factbook. Central Intelligence Agency (2014). Web. (accessed 23rd September 2014).

40. "Pacific Catastrophe Risk Assessment and Financing Initiative (PCRAFI): Risk Assessment - Summary Report". Asian Development Bank, Secretariat of the Pacific Community, World Bank. 2013.

41. Alpers (2004); for comparison countries: Small Arms Survey; 51-53.

42. “ASN Aviation Safety Database”. Aviation Safety Network (1996 - 2014). Web. (accessed 20th September 2014).

43. "Background to Fiji's four coups". BBC News. 5th December 2006. Accessed 6th September 2014.

44. "Cap - Anu". Rspas.anu.edu.au. 14th December 2012. Accessed 3rd September 2014.

45. Pacific Islands Forum Secretariat (2014). Web. (accessed 23rd September 2014).

46. Asia Pacific Medico-Legal Agencies (2013). Web (accessed 23rd September 2014).

47. “Disaster Victim Identification Guide”. INTERPOL (2009). Print.

48. Anon. Industry Connection (June 2010). Web. (accessed 28 August 2014).

49. Jowitt A (2008)The Future of Law in the South Pacific. Journal of South Pacific Law; 12: 43-48.

50. Powles G (1988) 'Law, Courts and Legal Services in Pacific Societies'. In: Powles G and Pulea M (eds). Pacific Courts and Legal Systems. Rev. ed. 